\title{
Correction to: A frame of analysis for collective free improvisation on the bridge between Husserl's phenomenology of time and some recent readings of the predictive coding model
}

\section{Lucia Angelino ${ }^{1,2}$}

Published online: 28 October 2019

(C) Springer Nature B.V. 2019

Correction to: Phenomenology and the Cognitive Sciences https://doi.org/10.1007/s11097-019-09640-7

The original version of this article unfortunately contains incorrect data.

Page 4, first paragraph, line 1: the term "All" has been corrected.

Page 12, fifth paragraph, line 31: the location "there are:" has been deleted and placed in the third paragraph, line 13.

Publisher's note Springer Nature remains neutral with regard to jurisdictional claims in published maps and institutional affiliations.

The online version of the original article can be found at https://doi.org/10.1007/s11097-019-09640-7

Lucia Angelino

lucia.angelino@aias.au.dk

1 Aarhus Institute of Advanced Studies (AIAS), Aarhus University, Høegh-Guldbergs Gade 6B, DK-8000 Aarhus C, Denmark

2 University Paris 1 Pantheon - Sorbonne, Paris, France 